\title{
Extracellular Vesicles and the Promise of Continuous Liquid Biopsies
}

\author{
Don Armstrong ${ }^{1}$ \\ Derek E. Wildman ${ }^{1,2}$ \\ ${ }^{1}$ Carl R. Woese Institute for Genomic Biology, \\ University of Illinois at Urbana-Champaign, \\ Urbana, IL; ${ }^{2}$ Department of Molecular and \\ Integrative Physiology, University of Illinois at \\ Urbana-Champaign, Urbana, IL, USA
}

Received: April 1, 2017

Revised: May 13, 2017

Accepted: May 21, 2017

Corresponding Author

Derek E. Wildman, MD

Department of Molecular and Integrative Physiology, University of Illinois at Urbana-Champaign, $1206 \mathrm{~W}$ Gregory Drive MC-195, Urbana, IL 61801, USA

Tel: +1-217-300-0939

E-mail: wildmand@illinois.edu
The rapid and accurate diagnosis of patients with minimally invasive procedures was once only found in science fiction. However, the discovery of extracellular vesicles (EVs) and their near ubiquity in body fluids, coupled with the advent of inexpensive next generation sequencing techniques and EV purification protocols, promises to make science fiction a reality. Purifying and sequencing the RNA content of EV from routine blood draws and urine samples are likely to enable pathologists and physicians to diagnose and track the progress of diseases in many inaccessible tissues in the near future. Here we present the evolutionary background of EV, summarize the biology of EV formation and cargo selection, and discuss the current barriers to making continuous liquid biopsies through the use of EV a science reality.

Key Words: Exosomes; Microvesicles; Extracellular vesicles; Cell-free RNA; Liquid biopsy
The production and release of membrane-bound vesicles by cells (which we will refer to generally as extracellular vesicles $[\mathrm{EVs}]$ in this review) is a process found in members of all three domains, including Archaea, ${ }^{1,2}$ Bacteria, ${ }^{3-5}$ and Eukaryotes (Fig. 1) ${ }^{3-15}$ EVs contain a diverse complement of proteins, nucleotides, and lipids, ${ }^{16,17}$ perform a large variety of functions, including antigen processing, ${ }^{18}$ host-parasite communication ${ }^{19}$ and competition with other species, ${ }^{1}$ and are hypothesized to be formed by multiple mechanisms. ${ }^{8}$ The observation of EVs in fluids such as saliva, ${ }^{20}$ urine ${ }^{21}$ and blood ${ }^{22}$ as well as the visualization and selection of EVs released from many human cells and cell lines including placenta (syncytiotrophoblasts, ${ }^{23}$ HTR-8, and JEG- $3{ }^{24}$ ), kidneys, ${ }^{25}$ and blood cells (including lymphocytes, ${ }^{14}$ platelets, ${ }^{26}$ and reticulocytes $^{27}$ ) argues for the continued function of EV in humans when coupled with the history of convergent evolution and conservation of function of EVs. In this review, we will first present some of the current hypotheses for the functions of human-derived $\mathrm{EV}$, and second suggest how the phenomenon of EV production can be utilized for the remote sensing of inaccessible tissues and discuss the roadblocks to immediate utilization.

\section{PRODUCTION AND FUNCTION OF EXTRACELLULAR VESICLES}

EVs have been found in almost every human body fluid, ${ }^{28}$ including urine, ${ }^{21,29}$ blood, ${ }^{22,30}$ saliva, ${ }^{20,31}$ cerebrospinal fluid (CSF), ${ }^{32}$ synovial fluid, ${ }^{33}$ semen, ${ }^{34}$ breast milk, ${ }^{35}$ amniotic fluid, ${ }^{36}$ aqueous humor (from cadavers), ${ }^{37}$ lymph, ${ }^{38}$ and bronchoalveolar lavage fluid. ${ }^{39}$ Because of the ubiquity of EVs, the mechanism of production and the likely functions of EVs have been the subject of intense study.

\section{Production of extracellular vesicles}

Eukaryotes generate multiple kinds of EVs. The major classes include exosomes, which are generated from multi-vesicular endosomes (MVEs), shedding microvesicles, which originate from the plasma membrane, apoptotic blebs, which result from programmed cell death, and gesicles, which are produced by vesicular stomatitis virus and potentially incorporate specific cargo proteins. ${ }^{40}$ Exosomes are generated by the inward budding of MVEs and early endosomes which is mediated by the actions of endosomal sorting complexes required for transport (ESCRTs), ceramides, and tetraspanins. ${ }^{41}$ The inward budding results in the potentially selective incorporation of cytoplasmic components 


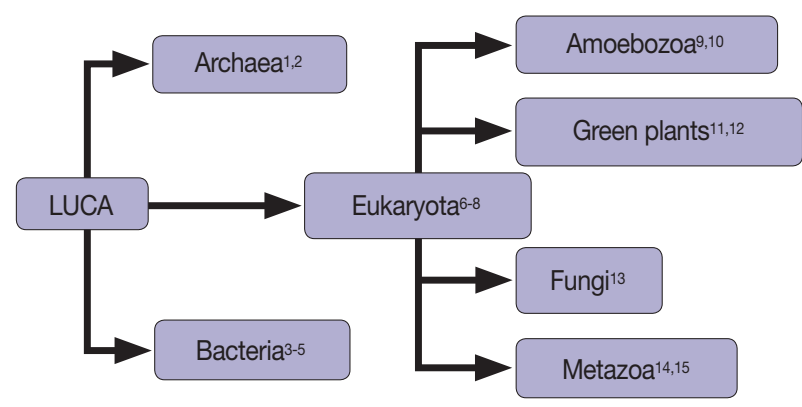

Fig. 1. Extracellular vesicles are found in all domains of life, including Archaea, ${ }^{1,2}$ Bacteria, ${ }^{3-5}$ and Eukaryotes..$^{3-15}$

including RNA, DNA, and proteins into the lumen of the exosome, as well as membrane lipids and transmembrane proteins. If the resultant MVEs are targeted to the plasma membrane instead of the lysosome, the fusion of MVEs with the plasma membrane leads to the release of exosomes. The fusion event is mediated by the action of multiple Rab proteins, including RAB27A (RAB27A, member RAS oncogene family), RAB35 (RAB35, member RAS oncogene family), and RAB11A (RAB11A, member RAS oncogene family $)^{42}$ in addition to the action of the cytoskeleton and fusion machinery (soluble NSF attachment protein receptors [SNAREs], etc.). ${ }^{41}$ The proteins involved in the processing of MVEs into EVs, including the ESCRTs, Rabs, and SNAREs, are present across the eukaryotes, which argues for EV production in at least the last common eukaryotic ancestor. The presence of orthologs of ESCRTs in archaea suggests that the last universal common ancestor may also have produced EVs. ${ }^{43}$ However, since these proteins are also essential to ubiquitination pathways, it is possible that the conservation of $\mathrm{EV}$ production is a by-product of the conservation of the targeting of proteins to the lysosome for degradation.

The budding of microvesicles from the plasma membrane requires the actin-myosin machinery and small GTPases such as ADP ribosylation factor 6 (ARF6), but does not appear to require ESCRTs, although there is evidence that ESCRT-I is associated with some microvesicles. Further advances in microscopy, including autofluorescence contrast microscopy, are likely to enable the visualization of $\mathrm{EV}$ production. ${ }^{44}$

\section{Cargo selection in extracellular vesicles}

The content of EVs often differs significantly from the cellular compartments from which the EVs are generated, both in terms of membrane composition and surface markers, as well as the contents of the lumen (RNA, DNA, and proteins) (Fig. 2). ${ }^{16,17}$ While some of the differences in membrane composition may be due purely to free energy considerations within the membrane

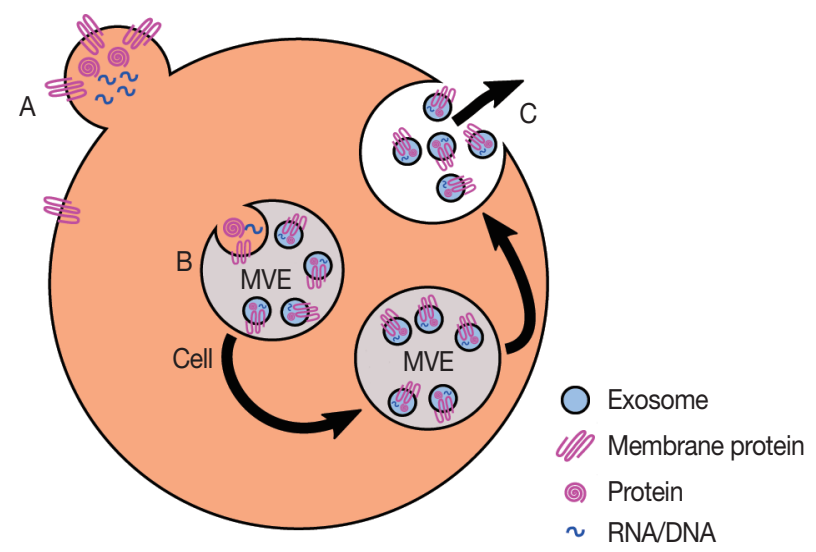

Fig. 2. Production of exosomes and microvesicles in cells. Microvesicles are generated from the budding of the plasma membrane (A). Exosomes are generated from the inward budding of multi-vesicular endosomes (MVEs) by the action of multiple proteins (B) and result in the release of exosomes (C) if the MVE is targeted to the plasma membrane instead of the late endosome.

such as curvature and charge, the enrichment of specific RNA motifs (ACCAGCCU, CAGUGAGC, and UAAUCCCA) ${ }^{45}$ and protein surface markers (epithelial cell adhesion molecule [EPCAM], Erb-b2 receptor tyrosine kinase 2 [ERBB2], protein tyrosine phosphatase, receptor type C [PTPRC], or CD63 molecule $[\mathrm{CD} 63])^{46}$ argues for the selective packaging of EV contents. Proteins that may fulfill the role of RNA sorting include members of the ESCRT-II complex as well as the RNA-induced silencing complex (RISC) (including trinucleotide repeat containing 6A [TNRC6A] and argonaute 2 [AGO2, RISC catalytic component $\left.]^{41,47}\right)$, but the complete picture of the RNA sorting is still unclear. For example, it is not yet clear whether the sorting of RNA into exosomes is for the primary purpose of export in $\mathrm{EV}$ or if it is a side effect of targeting RNA to the lysosome which is sometimes exploited to provide export in EV. Pulse-chase experiments with labelled RNA may help elucidate the kinetics of this transport, and thereby determine whether specific RNAs are targeted for secretion, or if the process is RNA agnostic.

\section{Function of extracellular vesicles}

There are multiple hypotheses for the ancestral function of EVs. The first set of hypotheses deal with the function of the content of EVs; the second with the need to enclose the content of EVs within vesicles, and the degree of importance of the vesicle membrane surface markers. EVs from gram-negative bacteria have been shown to contain Quorum sensing molecules, ${ }^{48}$ toxins (Shiga toxin, ${ }^{49} \mathrm{ClyA}^{50}$ ), and immune system modulators. ${ }^{5,8}$ Enteroparasites such as nematodes have also been shown to modulate innate immunity by transferring small RNAs (miR-100 and Y RNA) 
to mammalian cells. ${ }^{19,51}$

In humans, EVs can modulate the immune system by presenting antigens to antigen presenting cells (APCs) through internalization or fusion, being released by APCs to activate natural killer (NK), $\mathrm{CD}^{+} \mathrm{T}$, and $\mathrm{CD}^{+} \mathrm{T}$ cells, directly activating neutrophils, macrophages and NK cells, repressing immune responses through $\mathrm{CD}^{+} \mathrm{T}$ cells, NK cells, or myeloid derived suppressor cells, and finally by conveying opsonins and complement components to modulate phagocytosis and apoptotic cell phagocytosis. ${ }^{52}$ These mechanisms are even exploited by some cancer cells by releasing EVs which induce apoptosis of activated T cells. ${ }^{52}$ During human pregnancy, EVs with a distinct population of mRNA and miRNA are released from villous trophoblasts in the placenta; these EVs also contain FasL and TRAIL which promote apoptosis and subsequent immunosuppression of T cells. ${ }^{53,54}$ These EVs are likely utilized by the placenta to help maintain allograft tolerance during pregnancy. ${ }^{24}$

Using vesicles for packaging EVs can reduce the exposure of the contents to host proteases and antibodies, ${ }^{48}$ as well as coupling cargo with targeting receptors/agonists without requiring direct targeting molecule to cargo interactions. This mechanism of packaging hints at the vast potential of therapeutic cargo inside of EVs with specific surface markers for the treatment of many diseases, such as cancer, where a cargo needs to be delivered to a precise tissue or cell type which is otherwise difficult to access (Table 1). ${ }^{28}$

\section{EXTRACELLULAR VESICLES FOR DIAGNOSIS AND THERAPEUTICS}

\section{EVs in diagnosis}

\section{Diagnosing cancer using EVs}

The contents of EVs have been found to be modified in multiple different cancers, including colorectal cancer, ${ }^{77}$ prostate cancer, ${ }^{78,79}$ glioblastomas, ${ }^{61,80}$ and breast cancer, ${ }^{81}$ as well as many others (see Maas et al. ${ }^{82}$ for review). Multiple patents have already been filed to use the contents of EVs for diagnosis (see Urbanelli et $a l^{28}$ for review) so it is likely only a matter of time before EVs are used in the clinic for diagnosis.

\section{Remote sensor of inaccessible organs}

The most promising use of EVs is as a remote sensor of organs which are inaccessible to routine monitoring. In patients with breast cancer, EVs isolated from the serum contain higher levels of glypican 1 (GPC1); in patients with early pancreatic cancer,
Table 1. Tissues, cells, and fluids in which EVs have been identified as listed in Vesiclepedia ${ }^{76}$

\begin{tabular}{|c|c|}
\hline Tissue & Study \\
\hline Amniotic fluid & Keller et al. ${ }^{36}$ \\
\hline Aqueous humor & Stamer et al..$^{37}$ \\
\hline Ascites & Andre et $a . .^{55}$ \\
\hline Atherosclerotic plaques & Mallat et al. ${ }^{56}$ \\
\hline B cells & Miguet et al. ${ }^{57}$ \\
\hline Breast milk & Admyre et al.:35 \\
\hline Bronchoalveolar lavage fluid & Admyre et al..$^{39}$ \\
\hline Dendritic cells & Admyre et al..$^{39}$ \\
\hline Embryonic stem cells & Yuan et al. ${ }^{58}$ \\
\hline Endothelial cells & Deregibus et al. ${ }^{59}$ \\
\hline Epididymal fluid & Thimon et al. ${ }^{60}$ \\
\hline Glioblastoma cells & Skog et al. ${ }^{.1}$ \\
\hline Inflammatory fluids & Fourcade et al. ${ }^{62}$ \\
\hline Keratinocytes & Chavez-Muñoz et al. ${ }^{63}$ \\
\hline Liver stem cells & Collino et al. ${ }^{64}$ \\
\hline Lung cancer cells & Del Tatto et al. ${ }^{65}$ \\
\hline Macrophages & Yang et al. ${ }^{66}$ \\
\hline Malignant pleural effusions & Andre et al., ${ }^{55}$ Bard et al. ${ }^{67}$ \\
\hline Mesenchymal stem cells & Collino et al. ${ }^{64}$ \\
\hline Monocytes & Del Conde et al..$^{68}$ \\
\hline Mononuclear cells & Mack et al. ${ }^{69}$ \\
\hline Placenta & Gardiner et al. ${ }^{70}$ \\
\hline Plasma & Del Conde et al. ${ }^{68}$ Sabapatha et al..$^{71}$ \\
\hline Platelets & Heijnen et al. ${ }^{72}$ \\
\hline Red blood cells & Fourcade et al. ${ }^{62}$ \\
\hline Saliva & Ogawa et al.. ${ }^{20}$ Michael et al. ${ }^{31}$ \\
\hline Seminal fluid & Utleg et al. ${ }^{73}$ \\
\hline Serum & Skog et al. ${ }^{11}$ \\
\hline T cells & Martínez-Lorenzo et al. ${ }^{74}$ \\
\hline Trabecular meshwork cells & Stamer et al. ${ }^{37}$ \\
\hline Tracheobronchial cells & Kesimer et al. ${ }^{75}$ \\
\hline Urine & Cheng et al.., ${ }^{21}$ Keller et al.. ${ }^{36}$ Stamer et al. ${ }^{37}$ \\
\hline
\end{tabular}

For the most up-to-date list, see Vesiclepedia, ${ }^{76}$ EVpedia, ${ }^{17}$ and Exocarta. ${ }^{37}$

in addition to elevated GPC1, EVs contained mutant transcripts of KRAS (KRAS proto-oncogene, GTPase). ${ }^{83}$ EVs released by the placenta during pregnancies and identified in maternal blood (and potentially other body fluids, such as urine) will enable clinicians to routinely monitor the health of placentation and pregnancy throughout gestation without invasive tests. ${ }^{24,53,54,84}$ There is also mounting evidence that EVs package and may spread misfolded proteins associated with neurodegenerative diseases, which can be detected in CSF and blood, including the scrapie isoform of cellular prion protein (PrPsc) that is involved in Creutzfeldt-Jakob disease. ${ }^{85}$ EVs may potentially be useful in the diagnosis and progression tracking of similar neurodegenerative diseases.

\section{Typing of infections which are otherwise inaccessible}

Because the releasing of EVs is widely conserved in all three 
domains of life, it is possible that EVs which are present in accessible fluids, such as urine, saliva, or blood, may be of bacterial or fungal origins. Sequencing RNA present in EVs may identify the infectious agent responsible even though the source tissue is diffcult to access, enabling more effective treatment.

\section{Additional potential uses of EVs}

EVs which are introduced from an exogenous source have the potential to be used as the therapeutic agent, in much the same way as liposomes have been utilized. ${ }^{28,86}$ Because EVs can be generated using simple bioreactors using appropriate engineered cell lines coupled with immunoaffnity or other purification, ${ }^{87}$ EVs based therapeutics may prove to be more specific, uniform, and cheaper to produce than current liposome based technology. In theory, any transmembrane receptor or receptor agonist can be coupled with any other cargo which is small enough to fit into an EV and injected, potentially targeting widespread metastases or locations which are otherwise inaccessible to targeted therapeutics. ${ }^{28,86}$

\section{ROADBLOCKS TO FURTHER USE OF EXTRACELLULAR VESICLES IN DIAGNOSIS}

There are three distinct ways in which isolated EVs can be used in diagnosis. The first is a marker-only approach, where the concentration of the marker(s) in EV in the fluid of interest predicts disease or phenotype, and no other disease or healthy condition is likely to result in elevated concentrations of the marker(s). The second is a decomposition-based multi-marker approach, where the relative contribution of each tissue to the sub-sample of EVs is estimated using tissue-specific markers, and is correlated with differences in disease- or phenotype-relevant markers in that subsample. The third is a single-EV multi-marker approach, where single EV are interrogated to identify their tissue of origin and disease- or phenotype-relevant marker concentrations.

\section{EV isolation}

The methods of isolation currently used include ultracentrifugation, density gradient centrifugation, size exclusion through membranes, polymeric precipitation, immunoaffinity capture, and microfluidics. ${ }^{46,88,89}$ Ultracentrifugation is an easily executed protocol, but also results in the enrichment of proteins with high sedimentation rates which are not bound to exosomes, including major vault protein, heparan sulfate proteoglycan 2 (HSPG2), fatty acid synthase (FASN), and the $26 \mathrm{~S}$ proteasome..$^{88}$ Density gradient centrifugation reduces the contamination with high sedimentation rate protein complexes, but requires additional western blotting steps to verify that the density fraction isolated contains exosomes and has lower effciency than immunoaffinity capture.

Immunoaffinity capture using bead-conjugated antibodies to EPCAM or another exosome marker (such as ERBB2, PTPRC, or CD63) is simpler than density gradient centrifugation, and produces exosomes of high purity, but is limited to exosomal populations which express specific surface markers and may potentially miss novel exosome populations. Therefore, discovery experiments looking for novel populations of exosomes should use density gradient centrifugation, whereas established assays looking at known exosome populations can use appropriate immunoaffinity capture methods. Witwer et al. ${ }^{89}$ and future recommendations of the International Society for Extracellular Vesicles provide valuable recommendations for investigators examining EVs in humans.

\section{Normalization of EV content across tissues/samples}

For circulating miRNA, Fesler et al..$^{90}$ suggests uniform volumes of plasma or exogenous sequences and points out that endogenous control genes may vary between subjects (as well as in the control population).

\section{Identification of tissue of origin}

Because EVs located in body fluids can potentially originate from any source tissue for which there is a path to that fluid, accurate diagnostics of remote tissues also require identification of the tissue of origin of a particular EV or set of EVs. As the miRNA and mRNA contents of EVs came from cells in the originating tissue, miRNA and mRNA which are specific to those originating tissue but found within EVs in body fluid indicate that at least some of the EVs came from the original tissue. For example, the presence of high abundance placenta-specific transcripts such as LGALS14 in a sample of EVs would indicate that at least some of the EVs came from the placenta. Determining the fraction of EVs which are from a particular tissue of origin would allow for changes in miRNA and mRNA abundance over time to be assigned to a particular source tissue when multiple samples of different per-tissue abundances are obtained at a single timepoint. Marker-free (such as CellCODE ${ }^{91}$ ) and/or marker-dependent methods will likely be necessary to determine the proportion of exosomes which come from different source tissues in a mixed population.

\section{Quantification of a single EV}

In cases where the source tissue has not been assayed, an alterna- 
tive is the (much more diffcult) process of sequencing individual EV separately. Presumably, the advances in single-cell and single nucleus sequencing will provide the tools for single EV sequencing as a side benefit. Previous work by Smith et al..$^{92}$ using laser tweezers Raman spectroscopy that identified the lipid content of EVs on a per-EV basis identified multiple exosome subtypes which do not correlate strongly with the originating cell type, and therefore may represent different exosome subclasses which may be present in a single bulk exosome preparation. However, Raman spectroscopy is very slow and does not easily enable identification of the contents of exosomes. In an alternative approach, Kibria et al.$^{93}$ used micro flow cytometry after differential centrifugation to analyze CD44 (CD44 molecule) surface marker intensity on individual exosomes. This overcomes the limitations of typical flow cytometers, which can only detect minimum particle sizes of 200-500 nm, which is much larger than typical EVs. We suspect that the combination of micro flow cytometry with droplet based barcoding and sequencing techniques can enable the sequencing of the RNA contents of individual EVs in the nottoo-distant future.

\section{CONCLUSION}

EVs are poised to fulfill the promise of routine liquid biopsies in healthcare, whether used for diagnosing disease, tracking the effectiveness of therapy, or providing insight into multiple diseases as well as potentially tracking the progress of pregnancies in a non-invasive fashion.

\section{Conflicts of Interest}

No potential conflict of interest relevant to this article was reported.

\section{Acknowledgments}

We would like to thank the insightful comments of Priyadarshini Pantham and Monica Uddin on drafts of this manuscript. This work was funded in part by the National Institutes of Health 1R21ES027878-01 grant to DEW.

\section{REFERENCES}

\footnotetext{
1. Ellen AF, Rohulya OV, Fusetti F, Wagner M, Albers SV, Driessen AJ. The sulfolobicin genes of Sulfolobus acidocaldarius encode novel antimicrobial proteins. J Bacteriol 2011; 193: 4380-7.
}

2. Ellen AF, Zolghadr B, Driessen AM, Albers SV. Shaping the archaeal cell envelope. Archaea 2010; 2010: 608243.

3. Avila-Calderon ED, Araiza-Villanueva MG, Cancino-Diaz JC, et al. Roles of bacterial membrane vesicles. Arch Microbiol 2015; 197: $1-10$.

4. Haurat MF, Elhenawy W, Feldman MF. Prokaryotic membrane vesicles: new insights on biogenesis and biological roles. Biol Chem 2015; 396: 95-109.

5. Lai FW, Lichty BD, Bowdish DM. Microvesicles: ubiquitous contributors to infection and immunity. J Leukoc Biol 2015; 97: 237-45.

6. Lopez-Verrilli MA, Court FA. Exosomes: mediators of communication in eukaryotes. Biol Res 2013; 46: 5-11.

7. Lykke-Andersen S, Brodersen DE, Jensen TH. Origins and activities of the eukaryotic exosome. J Cell Sci 2009; 122(Pt 10): 1487-94.

8. Deatherage BL, Cookson BT. Membrane vesicle release in bacteria, eukaryotes, and archaea: a conserved yet underappreciated aspect of microbial life. Infect Immun 2012; 80: 1948-57.

9. Kriebel PW, Barr VA, Rericha EC, Zhang G, Parent CA. Collective cell migration requires vesicular trafficking for chemoattractant delivery at the trailing edge. J Cell Biol 2008; 183: 949-61.

10. Lavialle F, Deshayes S, Gonnet F, et al. Nanovesicles released by Dictyostelium cells: a potential carrier for drug delivery. Int J Pharm 2009; 380: 206-15.

11. Regente M, Corti-Monzón G, Maldonado AM, Pinedo M, Jorrín J, de la Canal L. Vesicular fractions of sunflower apoplastic fluids are associated with potential exosome marker proteins. FEBS Lett 2009; 583: 3363-6.

12. An Q, van Bel AJ, Huckelhoven R. Do plant cells secrete exosomes derived from multivesicular bodies? Plant Signal Behav 2007; 2: $4-7$.

13. Albuquerque PC, Nakayasu ES, Rodrigues ML, et al. Vesicular transport in Histoplasma capsulatum: an effective mechanism for trans-cell wall transfer of proteins and lipids in ascomycetes. Cell Microbiol 2008; 10: 1695-710.

14. Raposo G, Nijman HW, Stoorvogel W, et al. B lymphocytes secrete antigen-presenting vesicles. J Exp Med 1996; 183: 1161-72.

15. Lo Cicero A, Stahl PD, Raposo G. Extracellular vesicles shuffling intercellular messages: for good or for bad. Curr Opin Cell Biol 2015; 35: 69-77.

16. Choi DS, Kim DK, Kim YK, Gho YS. Proteomics of extracellular vesicles: exosomes and ectosomes. Mass Spectrom Rev 2015; 34: 474-90.

17. Kim DK, Kang B, Kim OY, et al. EVpedia: an integrated database of high-throughput data for systemic analyses of extracellular vesicles. J Extracell Vesicles 2013; 2: 20384.

18. Morelli AE, Larregina AT, Shufesky WJ, et al. Endocytosis, intracellular sorting, and processing of exosomes by dendritic cells. Blood 
2004; 104: 3257-66.

19. Coakley G, Maizels RM, Buck AH. Exosomes and other extracellular vesicles: the new communicators in parasite infections. Trends Parasitol 2015; 31: 477-89.

20. Ogawa Y, Kanai-Azuma M, Akimoto Y, Kawakami H, Yanoshita R. Exosome-like vesicles with dipeptidyl peptidase IV in human saliva. Biol Pharm Bull 2008; 31: 1059-62.

21. Cheng L, Sun X, Scicluna BJ, Coleman BM, Hill AF. Characterization and deep sequencing analysis of exosomal and non-exosomal miRNA in human urine. Kidney Int 2014; 86: 433-44.

22. Huang X, Yuan T, Tschannen M, et al. Characterization of human plasma-derived exosomal RNAs by deep sequencing. BMC Genomics 2013; 14: 319

23. Knight M, Redman CW, Linton EA, Sargent IL. Shedding of syncytiotrophoblast microvilli into the maternal circulation in pre-eclamptic pregnancies. Br J Obstet Gynaecol 1998; 105: 632-40.

24. Mitchell MD, Peiris HN, Kobayashi M, et al. Placental exosomes in normal and complicated pregnancy. Am J Obstet Gynecol 2015; 213(4 Suppl): S173-81.

25. Gerlach JQ, Kruger A, Gallogly S, et al. Surface glycosylation profiles of urine extracellular vesicles. PLoS One 2013; 8: e74801.

26. Wolf $P$. The nature and significance of platelet products in human plasma. Br J Haematol 1967; 13: 269-88.

27. Harding C, Heuser J, Stahl P. Receptor-mediated endocytosis of transferrin and recycling of the transferrin receptor in rat reticulocytes. J Cell Biol 1983; 97: 329-39.

28. Urbanelli L, Buratta S, Sagini K, Ferrara G, Lanni M, Emiliani C. Exosome-based strategies for diagnosis and therapy. Recent Pat CNS Drug Discov 2015; 10: 10-27.

29. Li M, Zeringer E, Barta T, Schageman J, Cheng A, Vlassov AV. Analysis of the RNA content of the exosomes derived from blood serum and urine and its potential as biomarkers. Philos Trans $\mathrm{R}$ Soc Lond B Biol Sci 2014; 369: 20130502.

30. Johnstone RM, Adam M, Hammond JR, Orr L, Turbide C. Vesicle formation during reticulocyte maturation: association of plasma membrane activities with released vesicles (exosomes). J Biol Chem 1987; 262: 9412-20.

31. Michael A, Bajracharya SD, Yuen PS, et al. Exosomes from human saliva as a source of microRNA biomarkers. Oral Dis 2010; 16: 34-8.

32. Vella LJ, Greenwood DL, Cappai R, Scheerlinck JP, Hill AF. Enrichment of prion protein in exosomes derived from ovine cerebral spinal fluid. Vet Immunol Immunopathol 2008; 124: 385-93.

33. Skriner K, Adolph K, Jungblut PR, Burmester GR. Association of citrullinated proteins with synovial exosomes. Arthritis Rheum 2006; 54: 3809-14.

34. Sullivan R, Saez F, Girouard J, Frenette G. Role of exosomes in sperm maturation during the transit along the male reproductive tract. Blood Cells Mol Dis 2005; 35: 1-10.

35. Admyre C, Johansson SM, Qazi KR, et al. Exosomes with immune modulatory features are present in human breast milk. J Immunol 2007; 179: 1969-78.

36. Keller S, Rupp C, Stoeck A, et al. CD24 is a marker of exosomes secreted into urine and amniotic fluid. Kidney Int 2007; 72: 1095102.

37. Stamer WD, Hoffman EA, Luther JM, Hachey DL, Schey KL. Protein profile of exosomes from trabecular meshwork cells. J Proteomics 2011; 74: 796-804.

38. Hood JL. The association of exosomes with lymph nodes. Semin Cell Dev Biol 2017; 67: 29-38.

39. Admyre C, Grunewald J, Thyberg J, et al. Exosomes with major histocompatibility complex class II and co-stimulatory molecules are present in human BAL fluid. Eur Respir J 2003; 22: 578-83.

40. Mangeot PE, Dollet S, Girard M, et al. Protein transfer into human cells by VSV-G-induced nanovesicles. Mol Ther 2011; 19: 1656-66.

41. Raposo G, Stoorvogel W. Extracellular vesicles: exosomes, microvesicles, and friends. J Cell Biol 2013; 200: 373-83.

42. Ostrowski EA, Shen $Y$, Tian X, et al. Genomic signatures of cooperation and conflict in the social amoeba. Curr Biol 2015; 25: 1661-5.

43. Leung KF, Dacks JB, Field MC. Evolution of the multivesicular body ESCRT machinery: retention across the eukaryotic lineage. Traffic 2008; 9: 1698-716.

44. Tu H, Liu Y, Marjanovic M, et al. Concurrence of extracellular vesicle enrichment and metabolic switch visualized label-free in the tumor microenvironment. Sci Adv 2017; 3: e1600675.

45. Batagov AO, Kurochkin IV. Exosomes secreted by human cells transport largely mRNA fragments that are enriched in the 3'-untranslated regions. Biol Direct 2013; 8: 12.

46. Greening DW, Xu R, Ji H, Tauro BJ, Simpson RJ. A protocol for exosome isolation and characterization: evaluation of ultracentrifugation, density-gradient separation, and immunoaffinity capture methods. Methods Mol Biol 2015; 1295: 179-209.

47. Gibbings DJ, Ciaudo C, Erhardt M, Voinnet O. Multivesicular bodies associate with components of miRNA effector complexes and modulate miRNA activity. Nat Cell Biol 2009; 11: 1143-9.

48. Aldick T, Bielaszewska M, Uhlin BE, Humpf HU, Wai SN, Karch H. Vesicular stabilization and activity augmentation of enterohaemorrhagic Escherichia coli haemolysin. Mol Microbiol 2009; 71: 1496508 .

49. Dutta S, Iida K, Takade A, Meno Y, Nair GB, Yoshida S. Release of Shiga toxin by membrane vesicles in Shigella dysenteriae serotype 1 strains and in vitro effects of antimicrobials on toxin production and release. Microbiol Immunol 2004; 48: 965-9. 
50. Wai SN, Lindmark B, Söderblom T, et al. Vesicle-mediated export and assembly of pore-forming oligomers of the enterobacterial ClyA cytotoxin. Cell 2003; 115: 25-35.

51. Buck AH, Coakley G, Simbari F, et al. Exosomes secreted by nematode parasites transfer small RNAs to mammalian cells and modulate innate immunity. Nat Commun 2014; 5: 5488.

52. Greening DW, Gopal SK, Xu R, Simpson RJ, Chen W. Exosomes and their roles in immune regulation and cancer. Semin Cell Dev Biol 2015; 40: 72-81.

53. Mincheva-Nilsson L, Baranov V. Placenta-derived exosomes and syncytiotrophoblast microparticles and their role in human reproduction: immune modulation for pregnancy success. Am J Reprod Immunol 2014; 72: 440-57.

54. Stenqvist AC, Nagaeva O, Baranov V, Mincheva-Nilsson L. Exosomes secreted by human placenta carry functional Fas ligand and TRAIL molecules and convey apoptosis in activated immune cells, suggesting exosome-mediated immune privilege of the fetus. J Immunol 2013; 191: 5515-23.

55. Andre F, Schartz NE, Movassagh M, et al. Malignant effusions and immunogenic tumour-derived exosomes. Lancet 2002; 360: 295305.

56. Mallat Z, Hugel B, Ohan J, Lesèche G, Freyssinet JM, Tedgui A. Shed membrane microparticles with procoagulant potential in human atherosclerotic plaques: a role for apoptosis in plaque thrombogenicity. Circulation 1999; 99: 348-53.

57. Miguet L, Pacaud K, Felden C, et al. Proteomic analysis of malignant lymphocyte membrane microparticles using double ionization coverage optimization. Proteomics 2006; 6: 153-71.

58. Yuan A, Farber EL, Rapoport AL, et al. Transfer of microRNAs by embryonic stem cell microvesicles. PLoS One 2009; 4: e4722.

59. Deregibus MC, Cantaluppi V, Calogero R, et al. Endothelial progenitor cell derived microvesicles activate an angiogenic program in endothelial cells by a horizontal transfer of mRNA. Blood 2007; 110: $2440-8$.

60. Thimon V, Frenette G, Saez F, Thabet M, Sullivan R. Protein composition of human epididymosomes collected during surgical vasectomy reversal: a proteomic and genomic approach. Hum Reprod 2008; 23: 1698-707.

61. Skog J, Wurdinger T, van Rijn S, et al. Glioblastoma microvesicles transport RNA and proteins that promote tumour growth and provide diagnostic biomarkers. Nat Cell Biol 2008; 10: 1470-6.

62. Fourcade O, Simon MF, Viodé C, et al. Secretory phospholipase A2 generates the novel lipid mediator lysophosphatidic acid in membrane microvesicles shed from activated cells. Cell 1995; 80: 919-27.

63. Chavez-Muñoz C, Morse J, Kilani R, Ghahary A. Primary human keratinocytes externalize stratifin protein via exosomes. J Cell Bio- chem 2008; 104: 2165-73.

64. Collino F, Deregibus MC, Bruno S, et al. Microvesicles derived from adult human bone marrow and tissue specific mesenchymal stem cells shuttle selected pattern of miRNAs. PLoS One 2010; 5: e11803.

65. Del Tatto M, Ng T, Aliotta JM, et al. Marrow cell genetic phenotype change induced by human lung cancer cells. Exp Hematol 2011; 39 : 1072-80.

66. Yang M, Chen J, Su F, et al. Microvesicles secreted by macrophages shuttle invasion-potentiating microRNAs into breast cancer cells. Mol Cancer 2011; 10: 117.

67. Bard MP, Hegmans JP, Hemmes A, et al. Proteomic analysis of exosomes isolated from human malignant pleural effusions. Am J Respir Cell Mol Biol 2004; 31: 114-21.

68. Del Conde I, Shrimpton CN, Thiagarajan P, López JA. Tissue-factorbearing microvesicles arise from lipid rafts and fuse with activated platelets to initiate coagulation. Blood 2005; 106: 1604-11.

69. Mack M, Kleinschmidt A, Brühl H, et al. Transfer of the chemokine receptor CCR5 between cells by membrane-derived microparticles: a mechanism for cellular human immunodeficiency virus 1 infection. Nat Med 2000; 6: 769-75.

70. Gardiner C, Tannetta DS, Simms CA, Harrison P, Redman CW, Sargent IL. Syncytiotrophoblast microvesicles released from preeclampsia placentae exhibit increased tissue factor activity. PLoS One 2011; 6: e26313.

71. Sabapatha A, Gercel-Taylor C, Taylor DD. Specific isolation of placenta-derived exosomes from the circulation of pregnant women and their immunoregulatory consequences. Am J Reprod Immunol 2006; 56: 345-55.

72. Heijnen HF, Schiel AE, Fijnheer R, Geuze HJ, Sixma JJ. Activated platelets release two types of membrane vesicles: microvesicles by surface shedding and exosomes derived from exocytosis of multivesicular bodies and alpha-granules. Blood 1999; 94: 3791-9.

73. Utleg AG, Yi EC, Xie T, et al. Proteomic analysis of human prostasomes. Prostate 2003; 56: 150-61.

74. Martínez-Lorenzo MJ, Anel A, Gamen S, et al. Activated human T cells release bioactive Fas ligand and $\mathrm{APO} 2$ ligand in microvesicles. J Immunol 1999; 163: 1274-81.

75. Kesimer M, Scull M, Brighton B, et al. Characterization of exosomelike vesicles released from human tracheobronchial ciliated epithelium: a possible role in innate defense. FASEB J 2009; 23: 1858-68.

76. Kalra H, Simpson RJ, Ji H, et al. Vesiclepedia: a compendium for extracellular vesicles with continuous community annotation. PLoS Biol 2012; 10: e1001450.

77. Matsumura T, Sugimachi $\mathrm{K}$, linuma $\mathrm{H}$, et al. Exosomal microRNA in serum is a novel biomarker of recurrence in human colorectal cancer. Br J Cancer 2015; 113: 275-81. 
78. Hessvik NP, Phuyal S, Brech A, Sandvig K, Llorente A. Profiling of microRNAs in exosomes released from PC-3 prostate cancer cells. Biochim Biophys Acta 2012; 1819: 1154-63.

79. Bryant RJ, Pawlowski T, Catto JW, et al. Changes in circulating microRNA levels associated with prostate cancer. Br J Cancer 2012; 106: 768-74.

80. Saadatpour L, Fadaee E, Fadaei S, et al. Glioblastoma: exosome and microRNA as novel diagnosis biomarkers. Cancer Gene Ther 2016; 23: $415-8$.

81. Asaga S, Kuo C, Nguyen T, Terpenning M, Giuliano AE, Hoon DS. Direct serum assay for microRNA-21 concentrations in early and advanced breast cancer. Clin Chem 2011; 57: 84-91.

82. Maas SL, Breakefield XO, Weaver AM. Extracellular vesicles: unique intercellular delivery vehicles. Trends Cell Biol 2017; 27: 172-88.

83. Melo SA, Luecke LB, Kahlert C, et al. Glypican-1 identifies cancer exosomes and detects early pancreatic cancer. Nature 2015; 523: 177-82.

84. Salomon C, Yee S, Scholz-Romero K, et al. Extravillous trophoblast cells-derived exosomes promote vascular smooth muscle cell migration. Front Pharmacol 2014; 5: 175.

85. Coleman BM, Hill AF. Extracellular vesicles: their role in the packaging and spread of misfolded proteins associated with neurodegenerative diseases. Semin Cell Dev Biol 2015; 40: 89-96.

86. Lener T, Gimona M, Aigner L, et al. Applying extracellular vesicles based therapeutics in clinical trials: an ISEV position paper. J Extracell Vesicles 2015; 4: 30087.

87. Whitford W, Ludlow JW, Cadwell JJ. Continuous production of exosomes: utilizing the technical advantages of hollow-fiber bioreactor technology. Gen Eng Biotechnol News 2015; 35: 34.

88. Tauro BJ, Greening DW, Mathias RA, et al. Comparison of ultracentrifugation, density gradient separation, and immunoaffinity capture methods for isolating human colon cancer cell line LIM1863-derived exosomes. Methods 2012; 56: 293-304.

89. Witwer KW, Buzás EI, Bemis LT, et al. Standardization of sample collection, isolation and analysis methods in extracellular vesicle research. J Extracell Vesicles 2013; 2: 20360.

90. Fesler A, Jiang J, Zhai H, Ju J. Circulating microRNA testing for the early diagnosis and follow-up of colorectal cancer patients. Mol Diagn Ther 2014; 18: 303-8.

91. Chikina M, Zaslavsky E, Sealfon SC. CellCODE: a robust latent variable approach to differential expression analysis for heterogeneous cell populations. Bioinformatics 2015; 31: 1584-91.

92. Smith ZJ, Lee C, Rojalin T, et al. Single exosome study reveals subpopulations distributed among cell lines with variability related to membrane content. J Extracell Vesicles 2015; 4: 28533.

93. Kibria G, Ramos EK, Lee KE, et al. A rapid, automated surface protein profiling of single circulating exosomes in human blood. Sci Rep 2016; 6: 36502. 